\title{
Voces y cuerpos. El consultorio médico radial como espacio discursivo en el Perú*
}

María Mercedes Zevallos Castañeda ${ }^{1}$

CASTAÑEDA, M.M. Z. Voices and bodies: radio consulting as an arena for discourse in Peru. Interface Comunicação, Saúde, Educação, v. 3 n.4, 1999.

The radio consulting room is a virtual location for the meeting of doctor and patient. This being the case, what is revealed in it (the body) becomes a field reconstructed by the assorted lines of discourse voiced as from the position that one occupies in this virtual arena: that of the doctor or that of the patient. In this paper, we describe the various discourse strategies used in the construction of the body in time and in space, as well as the construction of multiple bodies within the arena of airwaves. Two key aspects are broached: the process of making intimate issues public as one of the characteristics of current society, and the consulting room as an arena where discourses concerning the body, from varied sources, meet and blend together, combine or oppose one another and reveal themselves as divergent.

KEY WORDS: radio, doctor/patient relationship.

El consultorio radiofónico se presenta como un lugar virtual de encuentro entre médico y paciente. Siendo así lo que es develado en él, el cuerpo, se convierte en un territorio reconstruido a través de los discursos distintos enunciados desde dos lugares: lugar del médico, lugar del paciente.

En el artículo describimos las distintas estrategias discursivas utilizadas desde cada lugar en relación al cuerpo en el tiempo y al cuerpo en el espacio, y la construcción así de múltiples cuerpos en el espacio radiofónico.

Abordamos dos aspectos importantes: el proceso de publicitación de los lugares íntimos como una característica de la sociedad de nuestro siglo y el consultorio como lugar donde discursos sobre el cuerpo que provienen de distintos lugares se encuentran y se fusionan, se mezclan o se rechazan y se evidencian distintos.

PALABRAS-CLAVE: radio, relaciones médico-paciente.

\footnotetext{
"El trabajo presentado hace parte de la tesis de maestría "Voces y Cuerpos" presentada en setiembre de 1997 a la Escola de Comunicação/ECO da Universidade Federal do Rio de Janeiro/UFRJ.

${ }^{1}$ Profesora de la Facultad de Ciencias y Artes de la Comunicación de la Pontificia Universidad Católica del Perú; investigadora de la Organización Benéfica Prisma.- Institución sin fines de lucro encargada de la promoción de la salud en el Perú.

E-mail:mzevallos@prisma.pe
} 


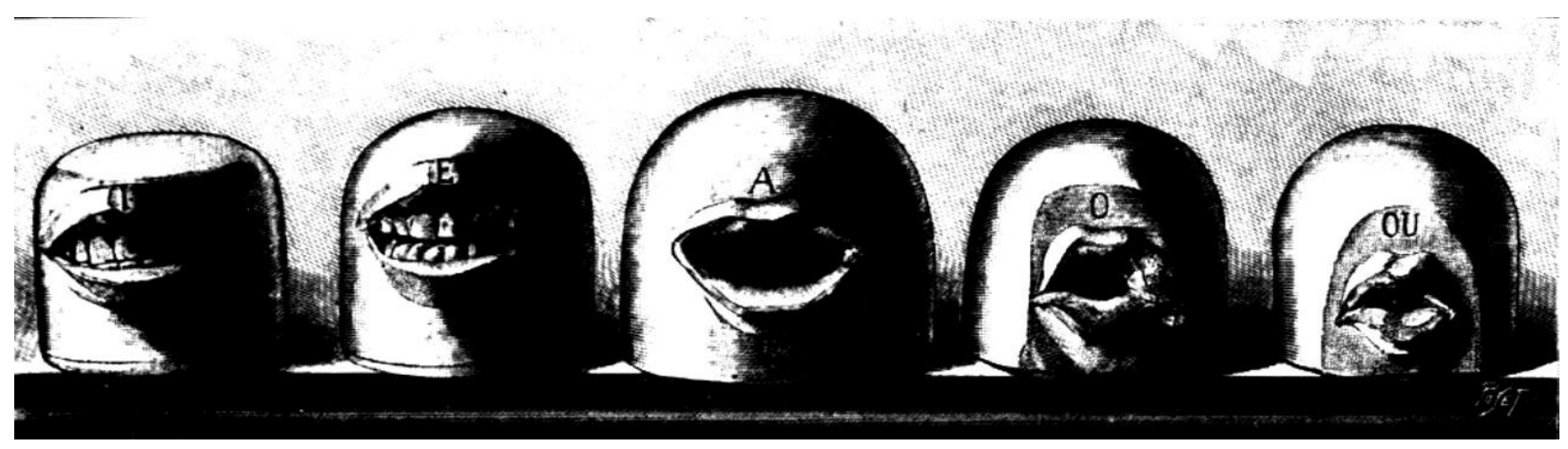

POYET, Pronúncia de vogais, 1908

Mi relación con la radio está marcada por lo afectivo. Cuando en mi ciudad, Cajamarca, al norte del Perú, no existía aún la televisión la radio era escuchada obligatoriamente en las mañanas en la casa de mis padres. Cerrando los ojos uno podía imaginar, dejar volar, abrir el subconsciente. La radio nos abría a la experiencia de ese lugar sonoro que nos recuerda el espacio interior.

Luego, ya formada en comunicación social, mi experiencia con la radio resultaría sumamente gratificante. El trabajo con el proyecto de radio Warmikuna Rimanchis 1 en la ciudad de Cuzco y la relación con las mujeres que lo producían implicó abrir una serie de interrogantes en torno al lugar de la radio en los medios de comunicación.

En un estudio de recepción realizado sobre el programa nos llamó la atención la manera como las mujeres construían su relación con la radio. Siendo una relación vivida como íntima (a pesar de compartir el espacio sonoro con la familia) se le demandaba información de cómo comportarse en la vida privada: con la familia, con los hijos, la pareja etc. $y$ en la radio las mujeres hablaban de problemas considerados íntimos y del orden de lo secreto: amores prohibidos, sufrimientos, pasiones; paradójicamente compartiéndolos con miles de oyentes.

Una de las demandas mayores de información de las mujeres era sobre la salud. Su cuerpo, considerado por nuestra cultura como un lugar secreto ( $y$ más aún en la cultura andina) era expuesto y develado en el lugar de lo público, a través de un formato muy difundido dentro de la radio peruana: el consultorio médico radial. Habría aquí dos lugares publicitados, el lugar del cuerpo y el lugar privado del consultorio médico.

Dentro de estos consultorios múltiples voces hablaban sobre el cuerpo: la voz de los médicos, la voz de la radio (a través de sus locutores) y la misma voz de los pacientes; para citar algunas.

La posibilidad de acercarnos a la comprensión de la relación entre lo público y lo privado que construía la radio y la construcción del cuerpo en el espacio mediático, a través del estudio de este espacio radial nos sedujo $e$ hicimos un estudio sobre las estrategias discursivas utlizadas para la construcción del cuerpo en el lugar de lo público.
${ }^{1}$ Warmikuna

Rimanchis es una frase tomada del quechua, lengua hablada en el sur del Perú. La traducción al español sería "Cuando las mujeres hablamos". 
Nuestro objeto de trabajo empírico son las prácticas discursivas que, sobre el cuerpo, se desarrollan en el caso de los consultorios médicos radiales "Servicio Profesional" emitidos por la emisora Radio Programas del Perú. Elegimos esta emisora al ser una de las cuatro con mayor cobertura en el país y ser un modelo seguido por muchas de las pequeñas emisoras locales.

\section{Características de Radio Programas del Perú}

El nacimiento de Radio Programas del Perú (RPP), al inicio de la década de los setenta, marcaría época en la historia de hacer radio en el Perú. La radio se caracteriza por su dinamismo y su capacidad para transmitir desde cualquier parte del país, recreando su identidad en razón de su capacidad para estar en todas partes y transmitir en el mismo momento que las cosas ocurren; así como por su apertura a la participación del público. Estas dos características pueden ser ejemplificadas con la manera como la radio trabajaba en los momentos en que el país, durante la década de los ochenta, sufría continuos cortes de fluido eléctrico causados por los continuos atentados terroristas. En estos momentos RPP se mantenía al aire, transmitiendo informaciones sobre los atentados que eran enviadas por los reporteros y los oyentes desde distintos puntos del país. Paralelamente el locutor animaba a los oyentes, pasaba mensajes de personas que se encontraban fuera de casa y consolaba a las personas que llamaban a la radio para no sentirse solas.

Muchas emisoras a lo largo de todo el país intentaron imitar el modelo propuesto por Radio Programas, resultando sumamente difícil imitar a una emisora con un enorme presupuesto para la producción.

Radio Programas del Perú se caracteriza por la transmisión de programas de noticias (aproximadamente $50 \%$ de su programación total), por lo tanto el género más usado es el informativo, situándose en segundo lugar el género participativo, usado en los consultorios radiales.

Los consultorios radiales basan su dinámica en un juego de pregunta y respuesta; la pregunta es formulada por teléfono, en todos los casos, y es respondida por un especialista sobre el tema que se viene tratando en el programa. En RPP existen consultorios sobre distintas temáticas: jurídico, médico, psicológico y religioso.

El consultorio radial que ahora nos ocupa es el dedicado a salud, que tiene una duración de una hora y se trasmite entre las 10 y 11 de la mañana de los días lunes y miércoles.

\section{Las estrategias discursivas en la construcción del cuerpo}

El cuerpo en el tiempo: descripción de la temporalidad de los relatos

Escuchando muchas veces el material de análisis (grabación de tres meses de programación) nos llamó la atención la manera como se construye la temporalidad en los relatos o más bien como ellos (los relatos) se construyen en temporalidades distintas para la radio, para los médicos y 
para los pacientes. Por tanto pensamos que la manera de construir la temporalidad en los relatos hace parte de una economía discursiva y tiene que ver con la construcción del cuerpo en el tiempo.

Las formas adverbiales son las que delimitan el lugar espacial y temporal en el discurso. En el caso de "Consulta Profesional" el discurso construido por sus locutores como un aquí (adverbio de lugar) y ahora (adverbio de tiempo) a la vez que señalan el lugar desde donde los locutores narran las noticias, también señalan la pluralidad del lugar espacio temporal que la radio construye; por tanto existe una experiencia múltiple del espaciotiempo en virtud de su característica de gran movilidad (varios locutores en distintos lugares del país). En el caso de los participantes del consultorio radial la radio se traslada del lugar central de la cabina a los lugares de las casas para construir también una "aquí y ahora" en el discurso de los participantes.

En el caso de los Consultorios médico radiales la radio construye una multiplicidad de lugares y de tiempos que coexisten en el espacio discursivo: el lugar de la casa, de la cabina, de la calle, de la oficina; el tiempo de lo cotidiano casero, de lo cotidiano profesional, el tiempo rápido, urgente de la noticia (de allí que se contemple, dentro de la economía discursiva de RPP espacios en los cuales puede entrar la noticia en cualquier momento). Dentro de esta multiplicidad de lugares espacio-temporales, parte de la economía discursiva del medio, se insertan discursos que siendo parte de esta economía tienen también características propias. Allí es donde ubicamos el discurso del médico y el del paciente.

Como vimos, los adverbios organizan las relaciones espacio temporales, en torno al sujeto de la enunciación, más que ello en torno a la instancia del discurso en la cual son producidos. En el caso del discurso del participante asistimos a la construcción de un tiempo que fluye y a un cuerpo que se transforma en el tiempo. Se narra alguna cosa que sucede con el cuerpo, por tanto tenemos una narrativa en la cual el cuerpo es el protagonista. En la acepción que Verón ${ }^{2}$ da al término diremos que estamos ante un discurso histórico, es decir que el participante produce una narrativa. La narrativa teniendo como característica su centralización en las marcas temporales (ayer, mañana, ahora, hoy, hacen dos meses, hace un ano etc.) como por ejemplo en el siguiente recorte:

\footnotetext{
Participante:... Mire se trata de lo siguiente, soy una mujer de 36 años, voy a cumplir y en junio del año pasado me hicieron una prueba antireumática y de artritis. ¿No? Salió negativo. Yo fui al seguro porque me dolía desde el codo hasta la muñeca, pero hace como dos días sentí un dolor espantoso, me dolía desde el codo hasta la muñeca horrible, en la mañana me he levantado, tomé una aspirina y un desinflamante pero no podía agarrar nada, si tocaba cualquier cosa para sujetar sentía dolor. O sea tuve que esperar varias horas el efecto, parece de la aspirina, y me pasó, todo el día ya no tuve malestar, ni rezagos de dolor.
}

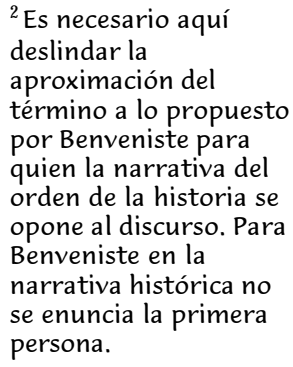


Es una narrativa que discurre fluidamente hasta llegar al tiempo presente, allí hay una parada, la fluidez desaparece para dejar espacios vacíos, invitaciones al interlocutor para completar el discurso, "lugares de discurso abiertos al imaginario del otro" (Verón, 1981, p.212)

El paciente anterior contínua así:

Ahora yo quisiera saber este dolor ya...primero lo tenía suave pero ahora último....hacen dos días, nunca había sentido el dolor así tan espantoso...

O en el siguiente ejemplo, en el cual también la narrativa está presente:

Participante: Bueno, estoy gestando, tengo tres meses, pero no sé cuando llega la hora de comer, después del almuerzo, después de la comida tengo un ligero dolor de, siempre, de estómago y va bajando al vientre y allí un dolor que no se me va.... ¿Por qué será?,...porque yo nunca he sufrido de dolor de estómago...

En el discurso de los pacientes anteriores podemos ver como el relato del paciente normalmente establece una temporalidad: antes, después y hoy. $Y$ el disturbio del cuerpo va evolucionando en el tiempo. La narrativa se produce desde un tiempo lejano hasta llegar a un presente, estableciéndose una especie de hitos en el transcurrir del tiempo (junio del ano pasado, hace dos días, en la mañana). El cuerpo enfermo pasa por un proceso en el tiempo que no es continuo sino marcado por etapas (por hitos). Por ejemplo en el siguiente párrafo:

Participante: Aló, buenos días doctor. Primeramente para agradecerle la consulta que le voy a hacer. Mire mi padre tiene 83 años. En el año 87 tuvo un derrame, él había tenido una pérdida auditiva, le vino un glaucoma en el año 88. Ahora se encuentra postrado. Pero el problema que ahorita presenta él es que aparte de su arteriosclerosis, que ya se pierde de la realidad, su vista, los párpados un poco que se le han caído, se encuentran completamente rojos ...

Igualmente en las siguientes participaciones:

Participante: Mire doctor, yo a los ocho años he tenido glomerulonefritis, a los 46 años me descubrieron una úlcera traquea-estómago. Pero ahora hace cinco días que estoy con cuarenta de fiebre...

Participante: “...el día viernes, el día viernes me desperté....de jueves para viernes, me desperté a las dos de la mañana..." Participante: Sabe que hará más o menos un mes, como por fines de diciembre tuve una

Experiência com sons em câmara morta

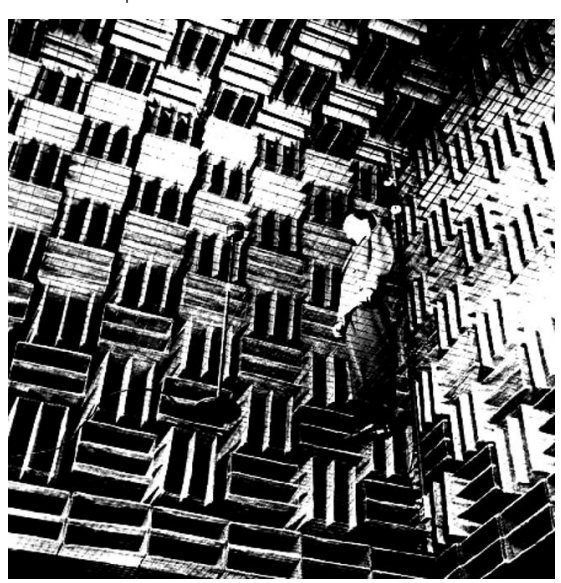

fevereiro, 1999 
infección al oído, me dio un dolor fuertísimo y bueno, me vio la doctora, (...) regresé y me dijo que no me había mejorado, me dio un antibiótico de 500, no me acuerdo el nombre, por ocho días más. Regresé, me dijo que estaba un poco mejor y me recetó Ruler, uno cada día por cinco días. Bueno, ya ha pasado menos de un mes y anoche sentí unas punzaditas, como una burbuja, como agua en el oído. Yo me he cuidado para que no me entre agua en la ducha, pero ¿qué será? ¿que no me ha hecho bien el remedio ese?

Es como si el cuerpo fuera sufriendo desórdenes continuamente hasta llegar a un momento de crisis, que coincide, en muchas de las participaciones, justamente con el momento de la llamada.

El discurso del médico se construye tanto en el pasado como en el presente, pero enfatiza cuando habla de un cuerpo presente ya desordenado (ya violentado), habla más bien de un estado del cuerpo (estado presente). El paciente, mientras tanto, narra un cuerpo que va sufriendo deterioro en el tiempo, de allí que se narra el pasado, se dice el presente y finalmente se pregunta: ¿qué ocurrirá?.

Médico geriatra: Personas similares al papá con relativa frecuencia se nos presentan en casa, o sea por encima de 75, 80 años que han presentado problemas de hipertensión de fondo y que han terminado con una embolia, que han terminado con una hemorragia que conocemos los médicos como accidente cerebro vascular. El drama que se presenta es después de esta circunstancia porque generalmente el paciente entra en un estado de inamovilidad, en un estado de postración que va acelerando una serie de deterioros que se vienen presentando ya en nuestro organismo.

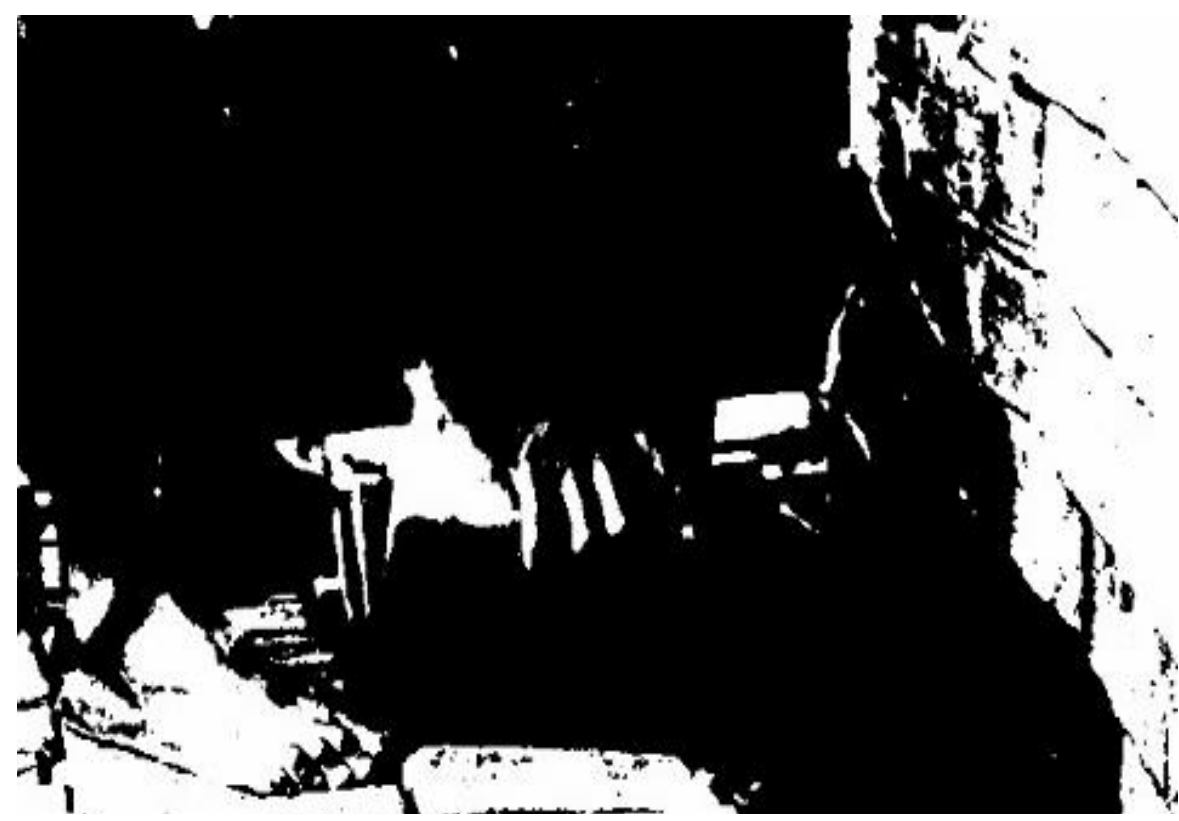


Médico:(...) mientras no tome antistamínicos por un tiempo no se le va a arreglar el problema que usted tiene en el oído, por que siempre va a seguir congestionada la rineo o faringe que es donde drena el agua que viene del oído entonces el líquido que se produce allí siempre va a ser un poco... por eso es que siente, lo que usted siente en el oído cuando por ejemplo pasa saliva, o cuando pasa alimentos, siente como una burbuja, usted bien lo ha dicho. Haga una prueba, suénese la nariz, pero tapándose la nariz, o sea como si quisiera estornudar pero tapándose la nariz, tapando la boca si usted llega a descomprimir los dos tímpanos quiere decir que está permeable pero si no descomprimen al mismo tiempo, quiere decir que uno de ellos no es permeable.

Concluyendo diríamos que existen dos temporalidades distintas cuando se habla del cuerpo en el consultorio radial: la del médico, descriptiva de un estado (por tanto el cuerpo como detenido en el tiempo) y la del paciente, narrativa de un proceso (por tanto el cuerpo que cambia en el tiempo).

\section{El cuerpo construído}

En este acápite nos referimos a las distintas maneras de construcción del cuerpo a través de la voz. Del recorte hecho al objeto vimos que existen múltiples estrategias discursivas utilizadas para referirse al cuerpo, las que evidencian maneras distintas de construcción del mismo. Nuestro interés aquí es registrar cuáles son las principales tendencias que se dan en este sentido.

\section{( Cuerpo particular y cuerpo tipo}

En un grupo de enunciados, tanto de participantes como de médicos, la referencia a la edad está presente. Para el paciente el cuerpo es particular, perteneciente a alguien y la edad se refiere a ese alguien, como en los enunciados siguientes: (mi hijo tiene doce años, tiene un año..., yo tengo 36 años).

Participante: mi bebé tiene año, cinco meses y su dentadura se ha cariado...

Participante: Ante todo muchísimas gracias por la respuesta que me va a dar. Mire mi hijo tiene doce años y come horrores, horrores realmente, pero se mantiene muy delgado, delgadísimo, casi se le puede ver hasta los huesos. Yo no sé a qué se debe eso. Y le gusta la sopa.

Participante: Doctor le agradezco de antemano la respuesta a mis preguntas. Quería saber doctor, soy una...bueno tengo 36 años y por primera vez estoy gestando, después de diez años de intentar embarazos. Tengo aproximadamente cuatro meses y medio de gestación y quisiera preguntarle si yo tengo ...si podría tener algún riesgo si yo viajo a Estados. 
Mientras que para los médicos la edad del cuerpo sirve para generalizar y referirse a un cuerpo tipo de una fase etarea, como especies de moldes en los cuales encaja el cuerpo, tal como lo menciona uno de ellos "...cada etapa de la vida tiene sus características...”. Tenemos los siguientes ejemplos:

Médico: Sí señora, usted en primer lugar no tiene que preocuparse por que esa es la característica general en los jóvenes a esta edad es la edad en donde se come como nunca. Ojalá le perdure esto, ¿no? pero cada etapa de la vida tiene también sus características, la característica de la adolescencia es precisamente comer bastante, casi incansablemente, ilimitadamente. Él debe también hacer ejercicios, hacer deportes seguramente y en esos deportes gasta todo lo que usted considera que ha sido una sobrealimentación y entonces conserva su forma. Mientras esté activo, mientras esté alegre, mientras tenga ganas de palomillar, de jugar, no debe usted preocuparse. La figura corporal va a permanecer así mientras dure la adolescencia, esto es normal absolutamente en esta época de la vida.

Médico:.... toda mujer que pasa de los 28 anos se le llama primeriza añosa, este es un término acuñado por los médicos...”

Si en el primer caso el cuerpo se construye en relación con el participante: mi bebé, mi hijo, tengo...; en el segundo caso el cuerpo es aquello de lo que se habla: ...los jóvenes a cierta edad, ... a partir de los 30. En el primer caso tenemos un cuerpo particular mientras en el segundo caso el cuerpo encaja en cierto tipo. Se postula entonces la existencia de tipos de cuerpo cuyas características los asemejan. En el primer caso se construye una relación de cercanía y en el segundo caso una relación de lejanía con el cuerpo en cuestión.

\section{[ Cuerpo íntegro, cuerpo desmembrado}

En el caso de los médicos tenemos que un grupo de enunciados se refiere al cuerpo como una estructura que tiene un equilibrio y que está conformada por partes. Como estructura el cuerpo tendrá una armazón central:”...es de la armazón del organismo"; partes centrales y secundarias, como el sistema venoso profundo y las arterias, partes simétricas (mitades, ojos, mamas, articulaciones, miembros), sustancias y tejidos (sustancias que entran, que son expulsadas, impulsadas, que limpian, tejido parenquital).

Pediatra: o sea la vitamina que le está dando y el fierro están muy bien indicadas. Ahora el síndrome de Dow señora, es una enfermedad constitucional, es estructural vamos a decir así, es de la armazón del organismo, en donde algunos de los cromosomas están alterados, esto ya no se puede corregir, no hay tratamientos... Ginecólogo: Cuando hablamos de una gestación estamos hablando de algo que impide el retorno venoso de los miembros inferiores hacia la oblicua derecha, el corazón. Esta sustancia que es la 
sangre nuevamente vuelve a ser impulsada, ser limpiada en los pulmones y expulsada nuevamente al torrente sanguíneo (...) hay que ver si estas venas están un poquito dilatadas porque existe un problema valvular o porque existe un problema obstructivo en el sistema venoso profundo que es el principal.

M.A. En el estudio de Midopinido que me han alcanzado se ve que mediante cintografía, que es una forma de marcar glóbulos rojos, se ha determinado que aumenta casi en un $60 \%$ la cantidad de sangre que entra al cerebro, al tejido parenquimal, de allí a que vayan a funcionar mejor las neuronas, ese es otro cantar. Ginecólogo: ...Bueno, le voy a responder muy simplemente. El cuerpo humano tiene algunos órganos, por decirlo así, pares, por ejemplo dos ojos, uno puede ver mejor con uno que con el otro, tiene dos mitades de la cara, una no es igual a la otra, así sucede también con la mama, una mama por razones muy particulares, es mucho más sensible a las hormonas que la otra mama... Médico: ...es raro que los problemas reumatológicos se acentúen en verano, son dos cosas en contra, pero también puede pasar. $Y$ como tercer factor es raro que sea solamente en un lado del cuerpo, generalmente los problemas reumatológicos son simétricos, vienen a ambos lados, mismas articulaciones, ¿no? Ya tiene tres factores en contra....

Lo que nos llama la atención en el grupo de enunciados es como la construcción del cuerpo como estructura implica que está compuesto por una serie de partes que, formando parte de ella, son tratadas en el discurso como piezas desglosables. Esta tendencia es mucho más clara cuando se habla sobre uno de los órganos del cuerpo, allí tendremos que éste es aún más seccionado. En el siguiente ejemplo se habla de componentes del cerebro: zonas corticales, vaso-dilatadores, neuronas.

Ginecólogo: Claro, mire con respecto a la plasticidad cerebral, yo trabajé con el doctor Esteban Roca y con el doctor Juan Franco en el Servicio de Neurocirugía, hace una barbaridad de años y encontramos que a veces lesiones de zonas corticales, encargadas de ciertas funciones, eran asumidas. Pero con respecto a los vasos dilatadores pueden mejorar la afluencia de sangre, lo interesante es la neurona. La neurona captará esto y mejorará su metabolismo.

Esta sectorización del cuerpo en partes implica también una sectorización del saber médico cuyas especialidades están definidas justamente por este cuerpo desmembrado. Un grupo de enunciados nos sirve como ejemplo: 
Ginecólogo: O sea que tiene un diagnóstico de hepatitis, señora. Hasta yo que soy ginecólogo me permito decir eso y con toda seguridad...

Médico General: Yo soy el más afín a lo que es cirugía de tubo digestivo...

Pediatra: También yo tengo que ver con todo lo que es el aparato reproductor...

En suma el cuerpo, en el discurso del médico, es un lugar conocido en tanto que es hurgado en sus detalles, se conoce sus componentes y se sabe su funcionamiento. El cuerpo es tratado como el lugar en el cual se trabaja. Esto queda mucho más explicado cuando el médico utiliza frases como "no se invade mucho", "se puede ver casi todo" que nos recuerdan el discurso de quienes exploran. El cuerpo es entonces también territorio explorado y explorable.

Ginecólogo: Tercero, la laparoscopia es un procedimiento de diagnóstico, quiere decir que no se invade mucho y se puede ver casi todo, así que está bien que se lo hayan hecho...

$Y$ como territorio y lugar de trabajo es susceptible de ser manipulado: arrancar, sacar, extirpar, extraer.

Médico: ...la magnitud de la caries debe ser bien grande para que quieran extraerlo.

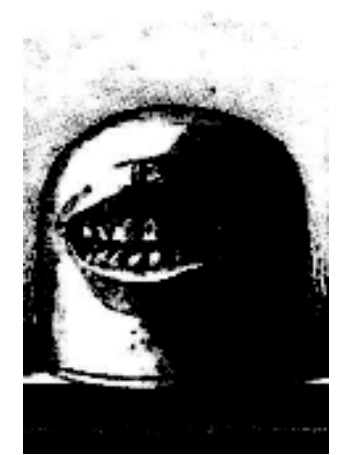

Médico: ..cuando los episodios de supuración son muy frecuentes, entonces está indicada la intervención. La extracción de esa glándula que ya dejó de ser glándula y se convierte en un foco infeccioso.

Médico: Bueno ya con dos ecografías y con el diagnóstico de saco aniembrionario ya no queda otro recurso que eliminar lo que no ha cuajado, ¿no? Allí no ha habido embrión, no ha habido embarazo, se ha formado placenta, se han unido embrión y óvulo, pero no ha cuajado, no se ha formado un niño, entonces pues hay que mejor sacarlo y esperar que usted en próximo mes o en dos meses quede usted nuevamente encinta.

En el caso del discurso del paciente el cuerpo, como por ejemplo en los enunciados siguientes, se construye como un lugar íntegro. En algunos enunciados referidos al dolor encontramos que éste (el dolor) está en alguna parte del cuerpo y se manifiesta de tal manera que, con su movilidad o por la aparición de otros síntomas, establece conexiones entre las zonas del cuerpo: “...va bajando...” , “...viene...”, “...también...”.

Participante: Buenos días, doctor Zucar. Mire hace cuatro años me ha dado un dolor bien fuerte en la espalda pero el doctor me dijo que era de enfriamiento, pero hasta ahora siento ese dolor, viene 
ese dolor a la espalda $y$ de pronto se me hinchan las manos y se me hinchan los pies.

Paciente: Doctor tengo 45 años, la regla se me ha empezado a retirar, se me retira ¿no? pero el dolor más fuerte lo tengo en los tobillos, caminar se me hace muy difícil, las piernas me duelen horrores. También me duelen las manos. Eso ha venido solamente con la regla, no tengo otro problema en cuanto a menopausia que yo sé que estoy dentro de ella, pero los tobillos es algo que...estoy ya dándome un trauma que prefiero quedarme sentada o echada y no puedo caminar.

En otro grupo de enunciados el discurso construye un cuerpo integral en tanto es un todo lo que se nombra: "todos los huesos...", "...toda la columna...", "...todo el cuerpo..."

Participante: Me fui a hacer ver y me han dado Nervit E pero me duelen ya todos los huesos, parezco una viejita de 80 años... Participante: doctor, cuando tomo alguna cosa con limón me empieza a doler todo el cuerpo...

Paciente: ...cuando yo tenía doce años, en un accidente me destrocé toda la columna...

El cuerpo es así construido como un sistema de relaciones, un conglomerado de órganos con conexiones entre ellos, y sobre todo es un lugar que se siente, cuya presencia es exacerbada por el dolor.

Sin embargo cuando se habla del cuerpo muerto, que para el caso del recorte hecho, solamente se presentó una vez (en la que se trató de la muerte de un joven cuya familia donó sus órganos); en este caso el paciente toma el discurso médico para desmembrar el cuerpo: "...la base del cráneo...", "cerebralmente..." (haciendo alusión a la muerte de una parte del cuerpo), "...los órganos " (y no el cuerpo). El cuerpo muerto, en este caso, ha pasado por un proceso de sectorización real que se traduce en el discurso utilizado.

Participante: mire mi hijo tuvo en diciembre un primer derrame cerebral, pero esta operación quedó bastante bien, estuvo recuperándose, con sus controles y todo. Ahora en marzo, el lunes pasado se puso mal lo llevé a emergencia, lo operaron pero ya parece que el derrame había sido en mucha cantidad, la sangre había dañado toda la base del cráneo me dijo el doctor, entonces me dijeron a las 5 de la tarde del martes que cerebralmente mi hijo había muerto, entonces el doctor me dijo en estos casos también se puede colaborar con la sociedad donando los órganos, que les parecería a ustedes (...) justamente cuando le contesté al doctor de mi respuesta que sí aceptaba la donación de los órganos, no solamente el corazón, hemos donado corazón, riñones y córneas; lo acepté...

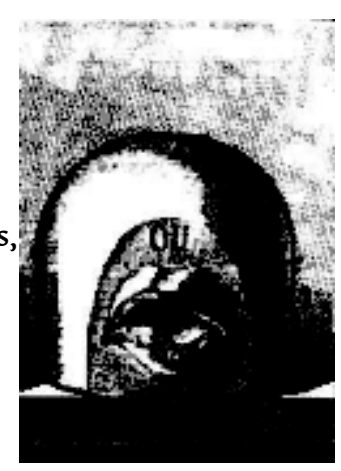


Por tanto el cuerpo muerto al ser traducido al discurso médico establece que su lugar ya no es el del paciente, es un cuerpo que, al ya no ser sentido, es cuerpo objeto por tanto posible de ser desmembrado.

\section{(4) Cuerpo interno, cuerpo externo}

En un grupo de enunciados, los participantes cuando se refieren al interior del cuerpo usan el discurso indirecto, marcando la situación de exterioridad del discurso, para lograr un efecto de sentido de transferencia de la responsabilidad a un otro. Vemos entonces cómo hay una separación entre un cuerpo externo, que sería de conocimiento del paciente, y un cuerpo interno ajeno a él. En este último caso la responsabilidad del discurso le compete al médico, de allí el uso del discurso indirecto. En los ejemplos frases como: “...me dijeron...", “...no me dijeron...", “...me dicen...”, “...me decían..." y el uso, en el caso del discurso oral, de otro tono de voz (en este caso ese cambio fue simbolizado con el uso de comillas) subrayan la procedencia externa del discurso. También marca la procedencia exterior del discurso el uso de otro registro discursivo, en este caso el discurso utilizado en los partes de análisis médicos o el lenguaje utilizado por los mismos médicos.

Participante: Buenos días, con el doctor Zucar. Mire mi pregunta es por que yo estoy en un tratamiento que me dicen que tengo una herida en el cuello del útero, mas antes me ha pasado lo mismo que me decían que tenía unas heridas y me lo cauterizaban, pero de repente me comienza a bajar bastante sangre y esta vez he ido donde la doctora, me he hecho el Papanicolau, me dice "no tú estás bien" pero ahora me ha vuelto a revisar y me dice "tu cuello del útero está de una forma que no es normal y aparte que se está desprendiendo por pedacitos". Pero en el Papanicolau me dice que todo está bien, o sea que no es nada de cáncer, que es el temor que uno tiene.

Participante: pero yo ayer he ido y ella me estaba revisando y me sacó y me mostró "mira" una cosita media blanca, ¿no? Y me dijo

"lo voy a mandar a patología

Participante: ...Ahora la descripción de la ecografía dice "anteverso flexo de superficie regular aumentado de tamaño contiene saco gestacional de $15 \mathrm{~mm}$. de tamaño, aún no se aprecia embrión". Eso es lo que me preocupa porque me dijo el doctor que ya debía notarse el embrión para este tiempo...

Se marca así la situación de exterioridad del discurso que se refiere al interior del cuerpo. Por tanto postulamos que el efecto de sentido buscado es de una no pertenencia del cuerpo interno, al ser quien habla de él una voz que viene de otro lado, una voz a quien es transferida la responsabilidad sobre ese cuerpo. 


\section{(1) Cuerpo que se ve, cuerpo que se siente}

En algunos de los trechos del transcurso de la conversación entre médico y paciente se evidencian dos maneras de construcción del cuerpo: una como sentimiento y la otra como ente físico separado del sentimiento. En el primer caso la ansiedad, la depresión, la tristeza, el miedo son parte constitutiva del discurso del participante y de su construcción de cuerpo, el cuerpo es sentido a través de ellos. Mientras que en el discurso de respuesta de los médicos todas estas sensaciones del cuerpo son relegadas como tales para pasar a ser traducidas como fenómenos de naturaleza física o ser ignoradas como parte del cuerpo. Tendremos entonces en los recortes del discurso a continuación que el miedo desaparecerá por un dosaje de alfa proteína; por tanto existe relación entre el fenómeno físico y la sensación; en el segundo ejemplo tendremos que la depresión está relacionada con falta de litio o con la menopausia y en el último ante el nerviosismo el médico responde con una respuesta esencialmente referida al fenómeno físico sin referirse a la sensación.

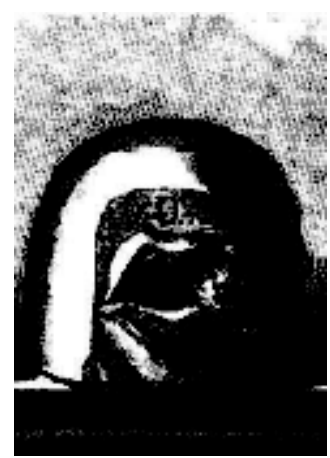

Participante: Doctor yo tuve un aborto. Doctor y no habría problema por ejemplo yo me he embarazado.

Ginecólogo: No, pues por eso, se hace usted un dosaje de alfa proteina y si la cantidad es normal usted olvídese de lo que tuvo con el bebé anterior.

Participante 10: Doctor sabe la última citomegalovirus total me ha salido 7.60 .

Ginecólogo: Usted tiene que olvidarse del citomegalovirus por que ya está embarazada.

Participante 10: Disculpe doctor pero tengo miedo que me vuelva a ocurrir lo mismo.

Ginecólogo: Bueno, las posibilidades son pequeñas, no es como una gran preocupación, pero yo entiendo el que tiene un trauma va a ser muy difícil quitárselo...y la manera de quitárselo es con dosaje de alfa proteína que le podría decir si hay un problema en el tubo neural.

Participante: Yo soy una persona de 37 años y cuando una semana antes de que me vaya a venir la regla se me hincha bastante, pero bastante el seno izquierdo, cuando ya me viene la regla se me va bajando, así como que se va desinflando. últimamente estoy muy olvidadiza, tengo mucho cansancio, dolor en la espalda y me siento muy depresiva y sensible, también tengo un poco de estreñimiento...

Ginecólogo: Ya, pero esto que me refiere usted ¿le sucede conjuntamente con las molestias de la mama o no? Participante: No, eso es antes o después pero cualquier momento me agarra la depresión. 
Ginecólogo: Eso puede tener dos motivos: o está baja de litio o ya le está agarrando la menopausia.

Participante: Quería una consultita, la semana anterior habló el doctor, no sé cual es su apellido, sobre un medicamento para el bitílico y yo quería ver para anotarlo porque a mí me ha ido casi bien con el ufadrin y Cofradrin pero se me hace muy...el sol,...no soy tan resistir por que hay que tener cuidado del sol, como transpiro tanto. Yo estoy bastante nerviosa, doctor. Yo quisiera ver si hay otro medicamento como el doctor lo había anunciado. Médico: Bitilico, es un término interesante, básicamente es un trastorno de pigmentación, falta melanina en la piel y entonces la piel se ve blanca. Ahora tratamientos en sí cuando existen muchos para un mismo problema es porque ninguno es bueno, cuando existe un solo tratamiento para un problema entonces este generalmente es bueno y todos lo utilizan.

Estas estrategias discursivas para dejar fuera del campo del discurso a la sensación como constructora del cuerpo se evidencia también en algunos trechos de conversación que refieren al dolor como constructor del cuerpo.

En el discurso del paciente la sensación del dolor es utilizada para referir un cierto órgano que se torna presente como sensación: la cintura, los ovarios, el corazón; para los médicos en cambio la sensación de dolor no implica la seguridad de estar referida al órgano nombrado por el paciente. El médico desautoriza la sensación, pues ella no da seguridades, de allí que se diga "...usted cree que ..." "...parece que..." pues el dolor refiere a otro lugar del cuerpo estableciendo conexiones.

Participante: Tengo 43 anos y me duele mucho la cintura doctor. Ginecólogo: Ya, la mayor parte de veces decimos la cintura o parece la parte de los riñones, pero generalmente es la columna.

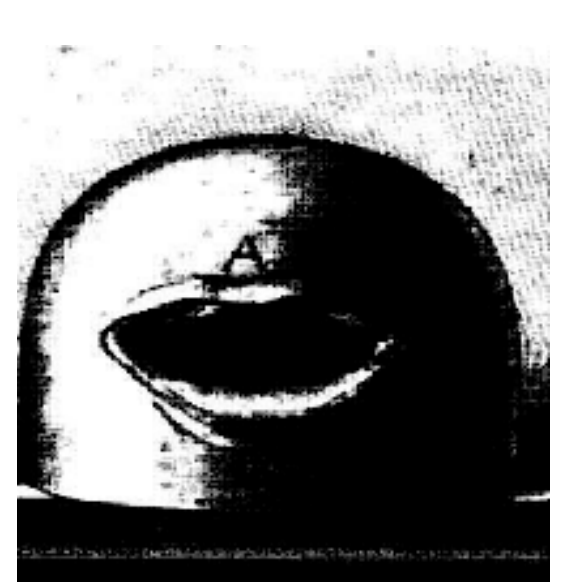

Después de los 38, 40 años cuando se tiene una gran actividad o mucho peso por ejemplo o uno se agacha indebidamente, querer tocar la punta de los pies, eso puede provocar dolor.

Participante: Doctor mire tengo muchos dolores en los ovarios, demasiados dolores y me hecho análisis $y$ todo sale bien $y$ estoy con la T de cobre hace 8 años.

Ginecólogo: El dolor a los ovarios es un dolor referido a su cuerpo y que usted cree que ahí se encuentran los ovarios. La mayor parte de veces son trastornos intestinales, son gastritis que se manifiestan a ese nivel y no son dolor a los ovarios.

En otro conjunto de enunciados referidos a los médicos vemos como la sensación es dejada de lado para privilegiar el ver, la mirada por tanto es sentida como constructora del cuerpo. En el caso de la radio la economía enunciativa del medio no permite el ver, por tanto se 
desarrollan, tanto por los médicos como por los participantes, una serie de estrategias encaminadas a la construcción de lo que nosotros hemos llamado “imágenes sonoras". El ritual del ver que forma parte del quehacer médico es recreado en el lugar del consultorio sonoro con el uso de comparaciones.

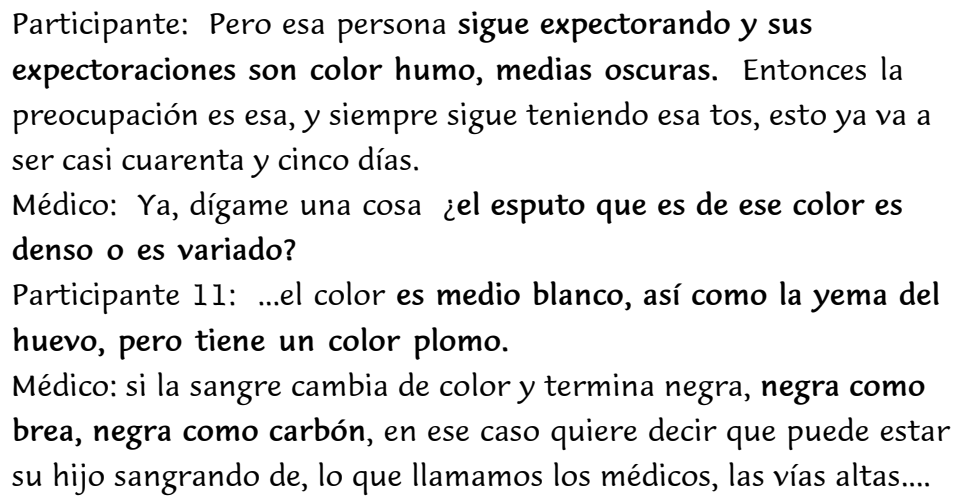

En algunos enunciados el médico plantea como imprescindible actuar sobre un cuerpo que es visto, su forma de conocer está afianzada sobre el ver y el medir. El médico por tanto debe ver, tiene obligación de ver; pero el dispositivo no le permite ver, por tanto no es permisivo y esto es enunciado como problema para la construcción del cuerpo. El cuerpo conocido es aquel cuerpo que es visto.

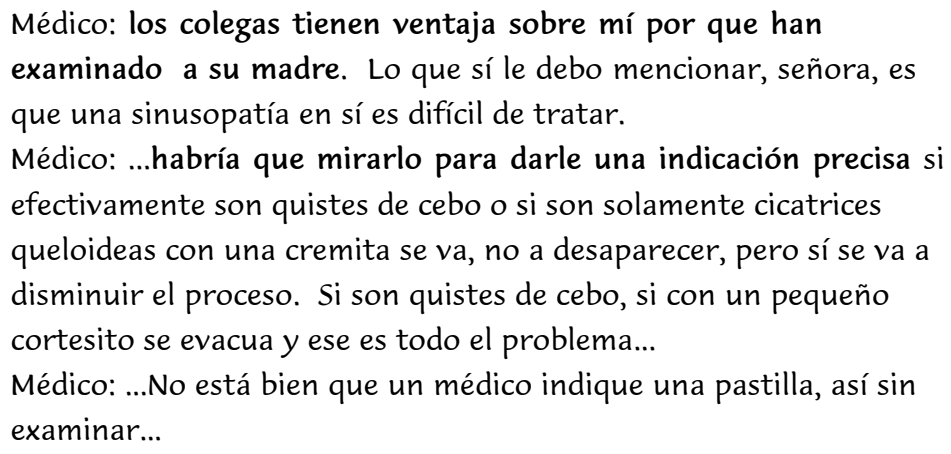

Como conclusión diremos que se evidencian dos maneras distintas de construír el cuerpo. Por un lado es un cuerpo que se ve, de parte de los médicos, y por otro un cuerpo que es sentido, de parte de los participantes.

\section{(1) El cuerpo que es y el cuerpo probable}

Hemos visto ya como el participante habla de un cuerpo que es sentido a través de la sensación de dolor, malestar, ansiedad etc.; en contraposición con esto el médico trabaja, en muchos de los enunciados, con un cuerpo probable, ya que es construido a través de la inseguridad, de la duda, de la probabilidad, que se manifiesta mediante frases como "...probablemente...", "....me parece que...", “...hacia un...". 


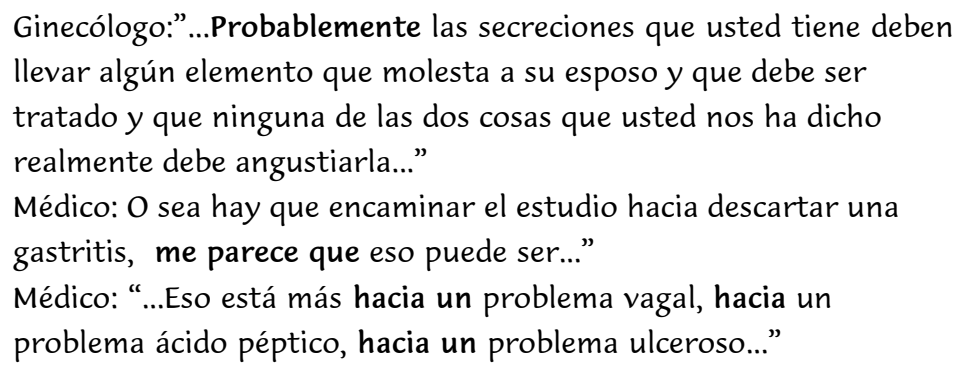

Hay por tanto desde el paciente un cuerpo que está, sobre todo cuando se manifiesta su presencia insoportable a través del dolor, un cuerpo que es, que existe insoportablemente. Para los médicos en cambio este cuerpo es un lugar de probabilidades, en él no existe ninguna certeza cuando se está enfermo. El cuerpo que escapa a la normalidad (es decir el cuerpo enfermo) es un cuerpo hecho de probabilidades de enfermedades.

\section{Secreto a voces}

El consultorio médico radial es un espacio polifónico construido no solamente con voces distintas sino con lugares múltiples desde los cuales se emite el discurso. Tanto voces como lugares pasan por un ordenamiento propio de la economía discursiva del espacio mediático instituyendo un ritual en el cual cada voz tiene un lugar y una función.

En lo referido a las estrategias en la construcción del cuerpo, dos posturas distintas se evidencian dependiendo del lugar desde el cual se emite el discurso. Los participantes-pacientes hablarán de un cuerpo esencialmente distinto al cuerpo del cual habla el médico. En el primer caso el médico describe un cuerpo en el tiempo presente, este es lugar del hacer de los médicos, donde es posible actuar (extraer, colocar, extirpar) y explorar. Como lugar de exploración el cuerpo debe ser visto y así conocido. En el segundo caso el participante-paciente va narrando como el cuerpo se transforma en el tiempo, el cuerpo es el lugar del ser, por tanto es sobre todo sensación, conocido a través de ella y no de la mirada.

Ambos cuerpos, ambas construcciones son puestos a disposición del espacio público en el cual se lo presenta a través de una suerte de complicidad. El lugar secreto del consultorio radial es expuesto, el secreto del cuerpo es desvelado. El receptor masivo es construido como el espía que escucha el secreto.

En conjunto las voces y lugares sonoros producen una pluralidad de sentidos casi simultáneamente. La radio se construye así como lugar no solamente de encuentro sino de lucha por voces que, viniendo de distintos lugares, dicen su discurso y evidencian el lugar de la radio como lugar de lucha por el sentido. En este caso la lucha se da teniendo como campo la morada más íntima, aquella que habitamos: nuestro cuerpo. Creo que por aquí se nos abre una veta a quienes nos interesamos por el tema de la comunicación y la salud y su espacio en los medios de comunicación. 


\section{Bibliografia}

ARAújO, I. A reconversão do olhar. Rio de Janeiro, 1996. 164p. Dissertação (Mestrado). Escola de Comunicação, Universidade Federal do Rio de Janeiro.

BAKHTIN, M.M. Estética da criação verbal. São Paulo: Fontes, 1992a.

BAKHTIN, M.M. Marxismo e filosofia da linguagem: problemas fundamentais do método sociológico na ciência da linguagem. 6.ed. São Paulo: Hucitec, $1992 b$.

BARTHES, R. O óbvio e o obtuso: ensaios críticos III. Rio de Janeiro: Nova Fronteira, 1990.

BENVENISTE, E. Problemas de linguística geral I . 3.ed. Campinas: Pontes, 1991.

FAUSTO NETO, A. O impeachment da televisão: como se cassa um presidente. Rio de Janeiro: Diadorim, 1995.

NUNES, M.R.F. O mito no rádio: a voz e os signos de renovação periódica. São Paulo: Annablume, 1993.

SCHNEIDER, M. Ladrões de palavras: ensaio sobre o plágio, a psicoanálise e o pensamento. Campinas: Unicamp, 1990.

VERÓN, E. A produção do sentido. São Paulo: Cultrix, 1980.

CASTAÑEDA, M.M.Z. Vozes e corpos: o consultório médico no rádio como espaço discursivo no Peru. Interface _ Comunicação, Saúde, Educação, v.3, n.4, 1999.

O consultório radiofônico apresenta-se como um espaço virtual de encontro entre médico e paciente. Assim sendo, o que é desvelado nele, o corpo, converte-se em um território reconstruído pelos distintos discursos enunciados a partir do lugar que se ocupa neste espaço virtual: o lugar do médico e do paciente.

Neste trabalho descrevemos as diferentes estratégias discursivas utilizadas na construção do corpo no tempo e no espaço e a construção de múltiplos corpos no espaço radiofônico. São abordados dois aspectos importantes: o processo de "publicização" dos espaços íntimos como uma característica da sociedade atual e o consultório como espaço onde discursos sobre o corpo, provenientes de lugares distintos, se encontram e se fundem, se misturam ou se opõem e se mostram divergentes.

PALAVRAS-CHAVE: rádio, relação médico-paciente. 


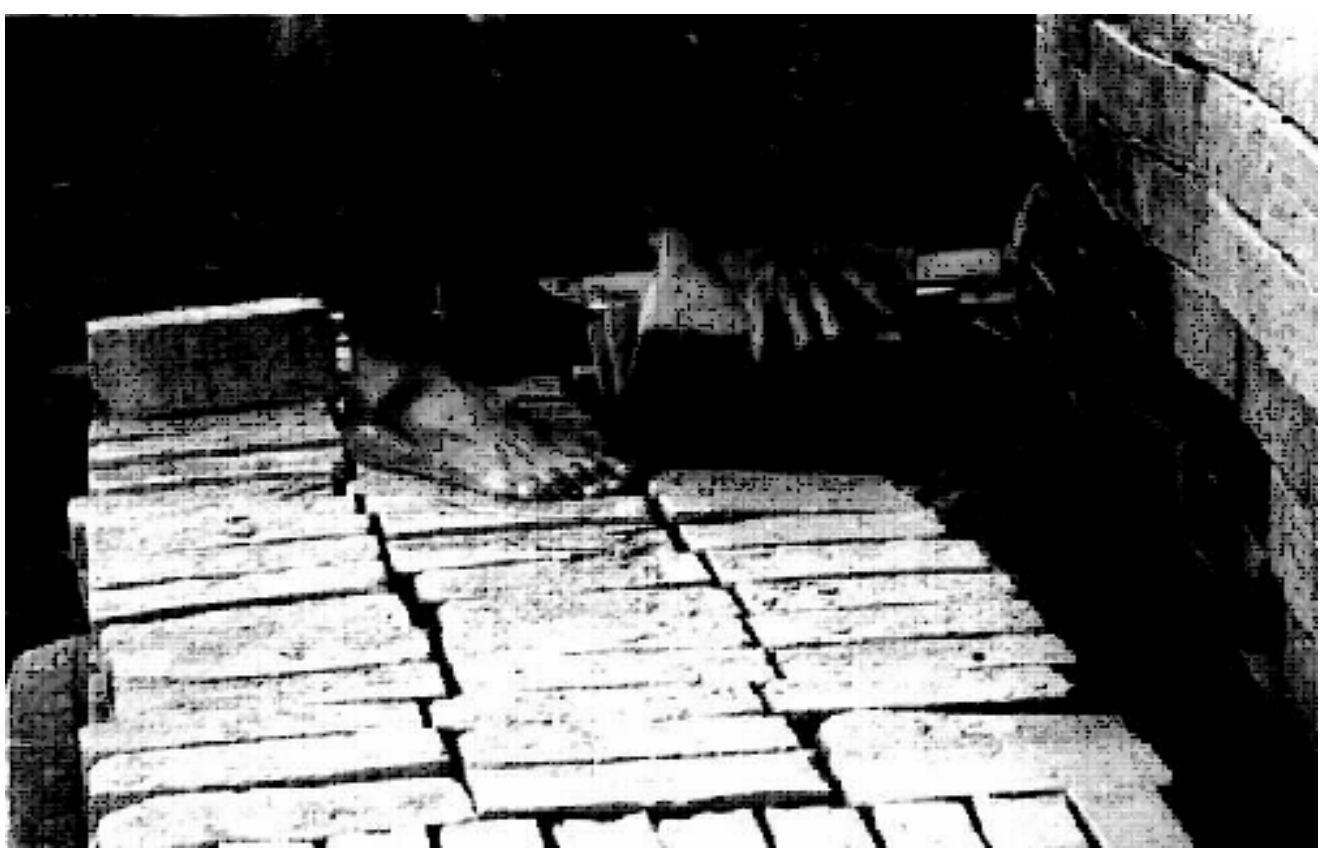

TRAJANO SARDENBERG, 1998

92 Interface-Comunic, Saúde, Educ 4 